\title{
Silindirle Sıkıştırılmış Atık Beton Agregasının Silindirle Sıkıştırılmış Beton Üretiminde Yeniden Değerlendirilmesi
}

\author{
İsmail KILIÇ*, Saadet Gökçe GÖK \\ Inşaat Mühendisliği Bölümü, Mühendislik Fakültesi, Kırklareli Üniversitesi, Kırklareli, Türkiye \\ (ORCID: 0000-0001-5556-512X) (ORCID: 0000-0002-7879-1610)
}

\begin{abstract}
Öz
Silindirle sıkıştırılmış betonlar (SSB), geleneksel betonlara göre daha yeni kullanılmaya başlanan bir yapı malzemesi olup kolay ve hızlı üretim, düşük maliyet, hammadde olarak geleneksel beton üretiminde kullanılan kaynakların kullanılabilmesi gibi avantajları açısından genellikle yol ve baraj inşaatlarında tercih edilmektedir. Geleneksel beton üretiminde olduğu gibi, SSB üretiminde de, kullanılan kaynakların korunması ve atık malzemelerin üretimde yeniden değerlendirilmesi; çevreye verilen zararın azaltılmasının yanı sıra, atık malzemelerin taşınması, depolanması ve çevreye zarar vermeyecek şekilde bertaraf edilmesi sırasında meydana gelen enerji kaybı ve maliyeti azaltmak açısından önemlidir. Bu çalışmada, silindirle sıkıştırılmış atık betonlar uygun boyutta öğütülerek yeniden SSB üretiminde kullanılmıştır. Atık agregalar iri agrega olarak \%0, \%50 ve \%100 oranlarında kullanılmıştır. Atık agregaların haricinde iri agrega olarak dolomit agregası, ince agrega olarak doğal kum, bağlayıcı olarak CEM I 42,5R Portland çimentosu ile su/çimento (s/ç) oranı 0,36 olan SSB üretimi gerçekleştirilmiştir. SSB numuneleri üretilirken her bir kademe yaklaşık 15 saniye süreli olmak üzere iki kademede sıkıştırma gerçekleştirilmiştir. Üretilen numuneler bir gün sonra kalıptan çıkarılmış, deney gününe kadar kür havuzunda kirece doygun suda bekletilmiștir. Üretilen betonların birim hacim ağılık, 7 ve 28 günlük basınç dayanımı, ultrases geçiş hızı, dinamik elastisite modülü ve aşınma direnci tayin edilmiştir. Deneysel çalışmanın neticesinde, atık SSB agregasının Los Angeles aşınma direnci, su emme gibi beton kalitesini belirleyen fiziksel özellikleri sağlama hususunda nispeten homojenlik sağlaması sayesinde, SSB üretiminde yeniden kullanım potansiyeli olduğu, bu şekilde yeniden değerlendirilen atık SSB agregalarının ekonomik yönden ve sürdürülebilirlik açısından katkı sağlayabileceği sonucuna varılmıştır.
\end{abstract}

Anahtar kelimeler: Atık Agrega, Silindirle Sıkıştırılmış Beton, Mekanik Özellikler, Fiziksel Özellikler, Sürdürülebilirlik.

\section{Re-evaluation of Waste Roller Compacted Concrete Aggregate in Production of Roller Compacted Concretes}

\begin{abstract}
Roller compacted concrete (RCC) is generally preferred for road and dam construction due to its advantages such as ease and speed of construction, ease of raw material supply and low cost. Conservation of resources and recycling of waste materials in the production of RCC, are important in terms of reducing energy losses and costs that occur during transportation, storage and disposal of wastes. In this study, RCC waste was crushed to the required aggregate sizes and reused in the production of RCCs. Waste aggregates were used as coarse aggregates in the amount of $0 \%, 50 \%$ and $100 \%$. In addition to waste RCC aggregates, dolomite aggregate was used as coarse aggregate. Natural sand was used as fine aggregate, and Portland cement CEM I 42.5R was used as binder in production of RCC with a water/cement ratio of 0.36 . The unit weight, compressive strength, ultrasonic pulse velocity, elastic modulus and abrasive wear resistance of the specimens were determined. As a result of the experimental study, it was concluded that the waste RCC aggregate provides relatively homogeneity in physical properties that determine concrete quality such as Los Angeles abrasion resistance and water absorption, so it has the potential to be reused in RCC production, and the re-evaluation of waste RCC aggregates can contribute for a sustainable and economical concrete production.
\end{abstract}

Keywords: Waste Aggregate, Roller Compacted Concrete, Mechanical Properties, Physical Properties, Sustainability.

*Sorumlu yazar: ismail.kilic@klu.edu.tr

Gelis Tarihi: 09.02.2021, Kabul Tarihi:02.07.2021 


\section{Giriş}

Silindirle sıkıştırılmış betonlar (SSB), düşük maliyet, hızlı ve kolay üretim gibi avantajlarıyla öne çıkan, geleneksel betona göre daha fazla miktarda agrega içeren ve taze halde sıfır çökmeye sahip karışımlardır [1]. Silindirle sıkıştırılmış betonlarda, saha koşullarını birebir temsil eden sıkıştırma prosedürünün laboratuvar koşullarında uygulanmasının zorluğu nedeniyle, sahadan alınan ve laboratuvarda üretilen numuneler farklı mekanik özelliklere sahip olabilmektedir [2]. Silindirle sıkıştırılmış betonların farklı yükleme hızları altındaki davranışlarına yönelik çalışmalar devam etmektedir [3-5].

Çevreye verilen zararları azaltmak ve üretimin devamlılı̆̆ını sağlayabilmek adına mühendislik uygulamalarında kullanılan malzemelerin sürdürülebilir olması önem arz etmektedir. Sürdürülebilir bir beton üretiminin gerçekleştirilebilmesi için üretimde kullanılan çimento miktarının azaltılması, geri dönüştürülmüş agregaların kullanılması ve arıtılmış atık suların beton karışım suyu olarak kullanılması önerilmektedir [6,7]. Silindirle sıkıştırılmış beton üretiminde çimento ile birlikte yüksek miktarda uçucu kül kullanıldığında, basınç ve çekme dayanımları yüksek, yapısal uygulamalarda, yol kaplamalarında ve büyük endüstriyel zeminlerde kullanıma uygun, Portland çimentosuna alternatif malzemeler elde edilebilmektedir [8]. Silindirle sıkıştırılmış betonlarda, agrega kısmi olarak uçucu kül ile değiştirildiğinde, uçucu kül miktarı arttıkça karışımın mukavemet değerleri, her yaşta, kontrol örneğine göre artmakta, beton boşluk hacminde azalma meydana gelmekte ve dürabilite özellikleri iyileşmektedir [9-11]. Sürdürülebilir beton üretimi için, atık malzemelerin agrega ya da bağlayıcı olarak silindirle sıkıştırılmış beton üretiminde değerlendirilmesine yönelik çalışmalar son yıllarda önem kazanmıştır [12$15]$.

$\mathrm{Bu}$ çalışmada, atık agregaların silindirle sıkıştırılmış beton üretiminde yeniden değerlendirilmesiyle sürdürülebilir bir beton üretimine katkı sağlanması amaçlanmıştır. Atık beton agregalarının yeniden kullanımının doğal kaynakların korunmasına yardımcı olarak ekolojik anlamda duyarlı, doğa dostu ve ekonomik bir beton üretimi konusunda fayda sağlaması beklenmektedir. Silindirle sıkıştırılmış beton üretiminde, iri agrega yerine tamamen atık beton agregası kullanıldığında bile elde edilen eğilme dayanımlarının, düşük yoğunluklu ağır vasıta trafiğinin bulunduğu yerler için yeterli olduğu, uygun çimento dozajıyla ve doğal agrega ile birlikte kullanıldığında daha yüksek eğilme dayanımları elde edilebildiği ve bu malzemenin ağır vasıta yoğunluğunun fazla olduğu yol uygulamalarında kullanılabileceği belirtilmiştir [16].

Doğal agregalarla daha yüksek basınç dayanımları elde edilebilmesine rağmen, agregaların Los Angeles aşınma değeri, su emme miktarı ve özgül ağırlık değeri, beton kalitesine büyük ölçüde etki eder ve bu değerlerin uygun olması durumunda, geri dönüştürülmüş beton yol agregalarının silindirle sıkıştırılmış beton uygulamalarında kullanılması mümkündür [17]. İnşaat, yenileme ve yıkım sonucunda artmakta olan geri dönüştürülmüş agregalar, performanslarının ve kökenlerinin çok çeşitli olması nedeniyle, yeniden kullanımı engelleyebilecek değişken özellikler sunmaktadır [18-20]. Agrega olarak yalnızca geri dönüştürülmüş beton agregası içeren SSB üzerinde gerçekleştirilen mekanik deneyler ve dayanıklılık testleri, bu tip betonun zamanla kabul edilebilir davranışa sahip olduğunu ve bu malzemenin alt temel inşaatı gibi yol yapım uygulamaları için uygun olduğunu göstermektedir [21].

Beton yol geri dönüştürülmüş agregaları, kaynağın göreceli homojenliğinden dolayı genellikle daha sabit özellikler sunduğundan bu atık agregaların yeniden kullanımı ve nitelendirilmesi daha kolaydır, bu malzeme, uygulamada, yol temeli inşaatlarında yer bulabilmektedir ancak çimento hamuru içeriğine bağlı olarak genellikle aşınma, yıpranma veya düşük mukavemet nedenleriyle kullanımı sinırlidır [17].

Beton üretiminde ya da silindirle sıkıştırılmış beton üretiminde atık beton agregasının kullanımına yönelik çalışmalar yaygın olmakla birlikte, geleneksel atık betonun geri dönüştürülmesiyle elde edilen agreganın uygun boyutlarda kırılması, elenmesi ve sınıflandırılması gerekliliği, atık agreganın su emme değerlerinin fazla olabilmesi, dayanım ve aşınma değerlerinin hedef kriterleri sağlayamaması gibi karşılaşılabilecek birtakım sorunlar, uygulamada bu agregaların kullanımını sinırlandırmaktır. Bu gibi olumsuz özellikler gösteren atık beton agregaları, dolgu malzemesi olarak kullanılabilmektedir. SSB, geleneksel betona kıyasla daha boşluksuz bir yapıya sahip olduğundan dayanım ve dayanıklılık özellikleri yönünden avantajlıdır. SSB'den elde edilen geri dönüşüm agregasının özellikleri daha iyi olacağından bu agrega ile üretilen betonun kalitesinin de iyi olması beklenmektedir. SSB atık agregalarının yeniden kullanımıyla atıkların geri dönüşümü ve tekrar kazanımı, çevresel açıdan önemli faydalar sağlayacaktır. 
Yol betonlarında, SSB üst kaplama malzemesi olarak kullanılmaktadır. Beton ile zemin arasında temel tabakası bulunduğundan, SSB toprak zemin ile doğrudan temas etmemektedir. Asfalt kaplamaların üst tabakasının belirli kalınlıkta kazınarak sıyrılması gibi, SSB yolların da üst tabakasının toprakla karışmadan kazınarak alınması mümkün olacaktır. Toprak ile karışan atık SSB'lerin ise yıkandıktan sonra kullanılması gerekecektir.

Silindirle sıkıştırılmış betonlar, maliyet ve hızlı üretim gibi avantajlara sahiptir. Yurtdışında özellikle son 50 yıldır yaygın olarak SSB üretimi yapılmasına rağmen, bu konu Türkiye'de nispeten yeni bir uygulama alanıdır. Ülkemizde SSB kullanımı sınırlı düzeyde olduğundan, silindirle sıkıştırılmış betonun geri dönüşümü üzerinde yapılan çalışmalar da kısıtlı seviyededir. Silindirle sıkıştırılmış beton, yol, saha betonu, baraj gibi mühendislik yapılarında kullanılabilmektedir. Bu beton kullanım ömrünü doldurduğunda, atık SSB'nin taşınması ve bertaraf edilmesi, çevresel ve ekonomik açıdan önem arz edecektir. Servis ömrünü tamamlayan silindirle sıkıştırılmış betonlar, geri dönüşüm agregası olarak hammadde kaynağı olacağından, silindirle sıkıştırılmış beton kullanımı arttıkça, SSB atık betonunun yeniden değerlendirilmesi konusu da yaygınlaşarak önem kazanacaktır.

Deneysel çalışmada, silindirle sıkıştırılmış atık betonlar, uygun boyutlarda kırılıp elenerek sinıflandırıldıktan sonra beton üretiminde agrega olarak yeniden değerlendirilmiştir. Geri dönüştürülmüş agregalarla silindirle sıkıştırılmış beton üretimi gerçekleştirilmiş, üretilen numunelerin birim hacim ağılık, 7 ve 28 günlük basınç dayanımı, ultrases geçiş hızı, dinamik elastisite modülü ve aşınma direnci belirlenmiş, silindirle sıkıştırılmış atık beton agregasının silindirle sıkıştırılmış beton üretiminde kullanım potansiyeli araştırılmıştır.

\section{Materyal ve Metot}

\subsection{Materyal}

Silindirle sıkıştırılmış beton (SSB) karışımında, Pınarhisar Limak Trakya Çimento fabrikasında üretilen CEM-I 42,5 R çimentosu, Kırklareli şebeke suyu, iri agrega olarak kireçtaşı (kalker) kökenli bir taş olan dolomit ve atık SSB agregası, ince agrega olarak ise doğal kum kullanılmıştır. Kullanılan çimentonun yoğunluğu $3,1 \mathrm{~g} / \mathrm{cm}^{3}$, doğal kumun yoğunluğu ise $2,72 \mathrm{~g} / \mathrm{cm}^{3}$ tür.

Atık agregalar, dolomit agregası kullanılarak laboratuvarda üretilen C 30/37 sinıfi SSB örneklerinin çeneli kırıcı ile agrega boyutuna getirilmesiyle elde edilmiştir. Kullanılan atık agregalar, saf dolomit agregasından farklı olarak SSB beton kırıklarından oluşmaktadır. Atık ve dolomit agregaları SSB üretiminde sadece iri agrega olarak kullanılmıştır. Atık ve dolomit agregaları karışımda kullanılmadan önce 4-8 mm, 8-12,5 mm ve 12,5-16 mm olmak üzere eleme yöntemiyle üç farklı gruba ayrılmıştır. Dolomit agregaları da aynı boyutlarda üç gruba ayrılmıştır. Bu gruplar kendi içerisinde ağırlıkça $\% 50$ oranında $4-8 \mathrm{~mm}, \% 40$ oranında $8-12,5 \mathrm{~mm}$ ve $\% 10$ oranında $12,5-16 \mathrm{~mm}$ olmak üzere karıştırılarak karışımın iri agrega kısmı elde edilmiştir. Bu şekilde atık agrega ile dolomit agregalarının gradasyonu benzer hale getirilmiştir. SSB karışımında iri agrega yaklaşı $\% 55$, ince agrega (doğal kum) ise yaklaşık $\% 45$ oranında kullanılmıştır. Bu oranlar, SSB üretiminde agrega maksimum dane çapının $\left(D_{\text {maks }}\right)$ daha küçük ve agrega granülometrisinin daha ince olması gerektiği için tercih edilmiştir. Agregaların fiziksel özellikleri Tablol'de verilmiştir. Tablo1'e göre atık beton agregasının su emme değerleri doğal agregaya göre yüksektir, bu durumun oluşmasında, atık agrega yüzeyinde bulunan çimento taneleri etkili olabilir. Yine de, geleneksel betonun geri dönüşümü ile elde edilen agregaların su emme değerlerine göre, silindirle sıkıştııılmış atık betonun kırılmasıyla elde edilen agregaların su emme değerlerinin daha düşük olduğu söylenebilir, burada, silindirle sıkıştırma işlemi sonucunda daha boşluksuz bir beton elde edilmesinin etkisi bulunmaktadır.

Tablo 1. Agregaların fiziksel özellikleri

\begin{tabular}{ccccc}
\hline Agrega türü & Birim hacim ağırlık $\left(\mathrm{g} / \mathrm{cm}^{3}\right)$ & Özgül ağırlık & Su emme (\%) & $\begin{array}{c}\text { Los Angeles aşınma } \\
\text { kaybı (LA) } \\
(\%)\end{array}$ \\
\hline Atık & 1,48 & 2,53 & 3,30 & 26,49 \\
Dolomit & 1,62 & 2,80 & 0,47 & 19,72 \\
\hline
\end{tabular}


Çalışmalarda üç farklı SSB karışımı üretilmiş ve $\mathrm{A}, \mathrm{AD}$ ve D olmak üzere kodlama yapılmıştır. Bu kodlamalarda,

A : Attk SSB agregas $\% 100$, dolomit agregas $1 \% 0$

$\mathrm{AD} \quad$ : Atık SSB agregas $\% 50$, dolomit agregas $\% 50$

D : Atık SSB agregası \%0, dolomit agregası \%100 oranlarında kullanılarak üretilmiş SSB karışımını göstermektedir. Silindirle sıkıştırılmış betonlar için karışım oranları Tablo 2'de belirtilmiştir.

Tablo 2. SSB tasarımı

\begin{tabular}{ccccccccc}
\hline $\begin{array}{c}\text { SSB } \\
\text { kodu }\end{array}$ & $\begin{array}{c}\text { Atık agrega } \\
(\%)\end{array}$ & S/Ç oran1 & $\begin{array}{c}\text { Su } \\
(\mathrm{kg})\end{array}$ & $\begin{array}{c}\text { Çimento } \\
(\mathrm{kg})\end{array}$ & $\begin{array}{c}\text { Doğal kum } \\
(\mathrm{kg})\end{array}$ & $\begin{array}{c}\% 50 \\
(4-8 \mathrm{~mm})\end{array}$ & $\begin{array}{c}\text { İri agrega }(\mathrm{kg}) \\
(8-12,5 \mathrm{~mm})\end{array}$ & $\begin{array}{c}\% 10 \\
(12,5-16 \mathrm{~mm})\end{array}$ \\
\hline $\mathrm{A}$ & 100 & 0,36 & 108 & 300 & 943 & 557 & 445 & 111 \\
$\mathrm{AD}$ & 50 & 0,36 & 108 & 300 & 943 & 586 & 469 & 117 \\
$\mathrm{D}$ & 0 & 0,36 & 108 & 300 & 943 & 616 & 493 & 123 \\
\hline
\end{tabular}

Her bir SSB türünde, 7 ve 28 günlük basınç dayanımı, ultrases geçiş hızı ve dinamik elastisite modülü tespiti için 6, aşınma direncinin tayini için 1 adet olmak üzere, 7 adet $15 \mathrm{~cm} \times 15 \mathrm{~cm} \times 15 \mathrm{~cm}$ küp beton numuneleri üretilmiştir. Toplamda 21 adet küp SSB numunesi üretilmiştir.

\subsection{Yöntem}

Atık SSB ve dolomit agregaları üzerinde agrega deneyleri yapılmış, ardından bu agregalar kullanılarak üretilen SSB numuneleri üzerinde sertleşmiş beton deneyleri gerçekleştirilmiştir.

Birim hacim ağırlık deneyi TS EN 1097-3 [22], agregada özgül ağırlık ve su emme oranı tayini TS EN 1097-6 [23], agrega parçalanma direnci tayini TS EN 1097-2 [24], beton karışım hesabı TS 802 [25], taze betonda çökme deneyi TS EN 12350-2 [26], basınç dayanımının belirlenmesi TS EN 123903 [27], ultrases geçiş hızının belirlenmesi ASTM C 597 [28] ve aşınma direnci tayini TS EN 1342 [29] standartlarına göre yapılmıştır.

Karışım hesabında çökme sıfır olacak şekilde, beton karışımları, su/çimento oranı 0,36 olarak tasarlanmıştır. Karışımlarda su ve çimento miktarları değişmemiş, agrega miktarları ise dolomit ve atık agregalarının yoğunluk farklılı̆̆ından dolayı miktarları değişkenlik göstermiştir. Agregaların suya doygun yüzey kuru durumu dikkate alınmıştır.

ASTM C 1435 [30] standardına göre silindirle sıkıştırılmış beton örneklerinin üretimi yapılmıştır. SSB numuneleri üretilirken her biri yaklaşı 15 saniye olmak üzere iki kademede sıkıştırılmıştır. Üretilen numuneler bir gün sonra kalıptan çıkarılmış, kırım günlerine kadar kür havuzunda kirece doygun suda bekletilmiştir.

Ultrases geçiş hızı ve dinamik elastisite modülü tespitinde Proceq marka Pundit PL-200 ultrasonik test cihazı kullanılmıştır. Bu testler için $15 \mathrm{~cm} \times 15 \mathrm{~cm} \times 15 \mathrm{~cm}$ boyutlu 28 günlük küp SSB numunelerinden yararlanılmıştır.

Aşınma direncinin belirlenmesinde, zemin kaplamalarında kullanılan doğal taş ve beton ürünlerinde aşınma direncinin belirlenmesi amacı ile tasarlanmış geniş diskli dikey aşındırma test cihazı kullanılmıştır. Cihazın $70 \mathrm{~mm}$ kalınlıkta bir diski mevcut olup 75 devir/dakika hızla dönmektedir. Test yapılırken aşındırıcı toz kullanılmıştır. SSB örneği yüzeyine, aşındırıcı toz ile birlikte sürtünerek dönen diskin, yüzeyde açmış olduğu oyuğun alt ve üst sınır çizgileri arasındaki mesafe $0,5 \mathrm{~mm}$ duyarlılıkta ölçülerek deney tamamlanmıştır. Bu mesafe, oyuğun derinliği ile bağlantılı olduğundan, TS EN 1342 [29] standardına uygun şekilde aşınma direnci değeri olarak alınmıştır. Ölçülen aşınma değeri, mm olarak verilmiştir.

\section{Bulgular ve Tartışma}

Betonu oluşturan bileşenlerin kalitesi, beton kalitesine doğrudan etki etmektedir. Tablo 1'de fiziksel özellikleri verilmiş olan geri dönüştürülmüş atık SSB agregalarının su emme değerleri doğal agregalara göre yüksektir fakat normal beton atık agregasına göre SSB atık agregasının su emme değerleri daha düşüktür. $\mathrm{Bu}$ nedenle, geri dönüştürülmüş agrega kullanıldı̆̆ında, kaynak olarak SSB kullanımının 
geleneksel beton kullanımına göre avantaj sağlayacağı söylenebilir. Agregaların beton üretiminde kullanılabilmesi için aşınma kaybı değerinin en fazla \%50 olması gerekir. SSB geri dönüşümü sonucu elde edilen atık agregalarda Los Angeles aşınma kaybı, \%26 olup önerilen sınır değere uygundur. Silindirle sıkıştırılmış betonların birim hacim ağıllık, 7 ve 28 günlük beton basınç dayanımı, ultrases geçiş hızı, dinamik elastisite modülü ve aşınma direnci değerleri Tablo 3'te verilmiştir. Silindirle sıkıştırılmış betonlarda beton basınç dayanımı değişimi Şekil 1'de gösterilmiştir.

Tablo 3. Deney sonuçları

\begin{tabular}{ccccccc}
\hline $\begin{array}{c}\text { SSB } \\
\text { kodu }\end{array}$ & $\begin{array}{c}\text { Birim hacim ağırlık } \\
\left(\mathrm{g} / \mathrm{cm}^{3}\right)\end{array}$ & $\begin{array}{l}\text { Basınç dayanımı }(\mathrm{MPa}) \\
7 \text { günlük }\end{array}$ & 28 günlük & $\begin{array}{c}\text { Ultrases } \\
\text { geçiş hızı } \\
(\mathrm{km} / \mathrm{s})\end{array}$ & $\begin{array}{c}\text { Dinamik } \\
\text { elastisite modülü } \\
(\mathrm{GPa})\end{array}$ & $\begin{array}{c}\text { Aşııma } \\
\text { miktarı } \\
(\mathrm{mm})\end{array}$ \\
\hline A & 2,12 & 19,6 & 27,9 & 3,64 & 28,83 & 24,5 \\
AD & 2,19 & 22,1 & 32,1 & 3,92 & 31,89 & 23,5 \\
D & 2,22 & 27,8 & 37,3 & 4,29 & 36,74 & 21,0 \\
\hline
\end{tabular}

Birim hacim ağırlık, basınç dayanımı, ultrases geçi hızı, dinamik elastisite modülü ve aşınma direnci değerlerinin en büyük olduğu numuneler $\% 100$ dolomit agregası ile üretilen numunelerdir. $\mathrm{Bu}$ numunelerde boşluk hacminin daha az olduğu ve bu durumun dayanım değerlerini olumlu yönde etkilediği söylenebilir. Aşınma direnci değerleri incelendiğinde, en fazla aşınmanın \%100 atık agrega ile üretilen numunelerde gerçekleştiği, aşınma direncinin doğal agrega kullanılarak üretilen numunelerde en fazla olduğu görülmektedir. Bu sonucun elde edilmesinde, atık agregalarda doğal agregalara nazaran Los Angeles aşınma kaybının fazla olmasının etkisi bulunmaktadır. Ayrıca, agrega ile çimento hamuru arasındaki bağın daha zayıf olması da aşınma değerlerinin daha fazla olmasına neden olabilir. Geri dönüştürülmüş agrega kullanılarak üretilen betonların basınç dayanımı ve dinamik elastisite modülü, kaynak olarak kullanılan betonun su/bağlayıcı oranına, çimento dozajına, agreganın kalitesine, betonun porozitesine diğer bir ifadeyle boşluk oranına, çimento hamuru-agrega aderansına bağlidır [31,32].

İri agrega olarak tamamen atık agrega kullanılan numunelerde, yalnızca dolomit kullanılarak üretilen numunelere kıyasla, birim hacim ağırlık değerinde $\% 4,50$ düşüş gerçekleşmiştir. $\% 50$ atık beton agregası, \%50 dolomit agregası ile üretilen numunelerde ise bu düşüş \%1,35 ile sinırlı kalmıştır.

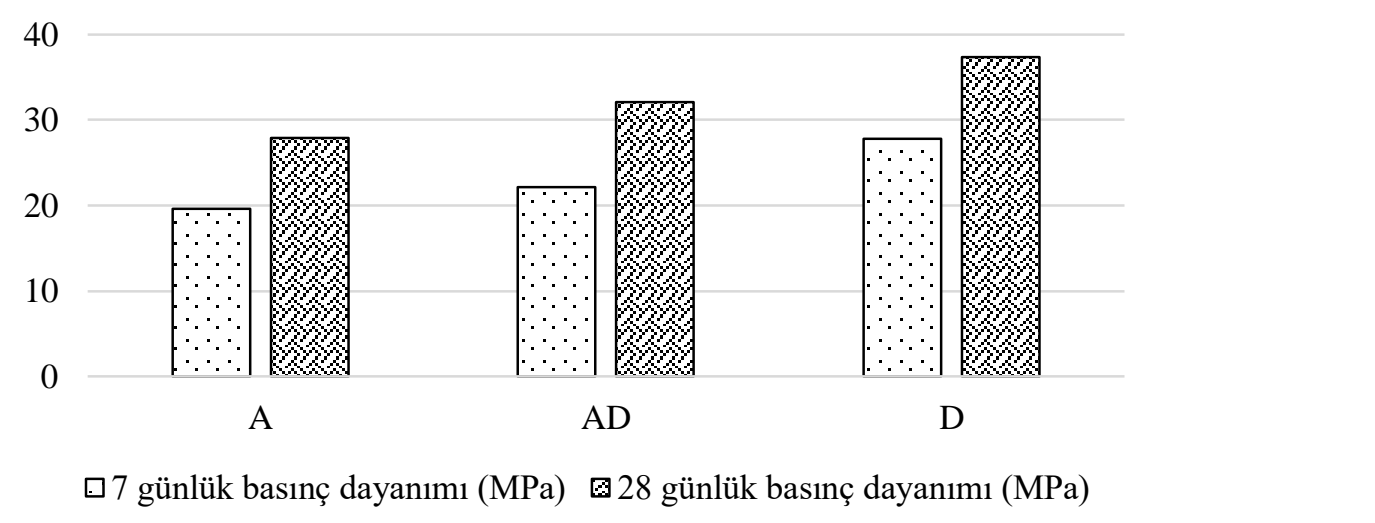

Şekil 1. Basınç dayanımı

7 günlük beton basınç dayanımları kıyaslandığında, iri agrega olarak yalnızca atık agrega kullanımının, yalnızca dolomit kullanılarak üretilen numunelere göre basınç dayanımında $\% 29,5$ azalmaya neden olduğu görülmektedir. \%50 atık agrega kullanımı ise 7 günlük basınç dayanımında $\% 20,5$ azalma ile sonuçlanmıştır. 28 günlük numunelerde de sonuçlar benzer eğilimdedir. İri agrega olarak \%100 oranında atık agrega kullanımı, yalnızca dolomit kullanılarak üretilen numunelere kıyasla basınç dayanımında $\% 25,2$ azalmaya neden olurken \%50 atık agrega kullanıldığında bu oran \%13,9 olmuştur.

Ultrases geçiş hızının belirlenmesi, betondaki boşluk miktarı hakkında bilgi veren tahribatsız bir deney yöntemidir. Betondaki boşluk miktarı arttıkça, ultrases geçiş hızı azalmaktadır. Bununla birlikte, betondaki boşluk oranının artması, beton basınç dayanımında azalmaya ve dürabilite özelliklerinin olumsuz etkilenmesine neden olur. İri agrega olarak tamamen atık agrega kullanılarak üretilen SSB 
numunelerde, yalnızca dolomit kullanılarak üretilen numunelere kıyasla, birim hacim ağırlık değerinde $\% 15,15$ azalma gözlenmiştir. \%50 atık agrega kullanımı ile bu azalma miktarı \%8,62 olmaktadır.

Silindirle sıkıştırılmış betonlarda, ultrases geçiş hızı ile beton basınç dayanımı arasında Şekil 2'deki gibi doğrusal bir ilişki olduğu görülmüştür. Ultrases geçiş hızı arttıkça, diğer bir ifadeyle betondaki boşluk miktarı azaldıkça, basınç dayanımı artmaktadır. Ultrases geçiş hızı ile basınç dayanımı arasındaki ilişki kuvvetlidir.

İri agrega olarak sadece atık agrega kullanılarak üretilen SSB numunelerde, yalnızca dolomit kullanılarak üretilen numunelere göre betonun dinamik elastisite modülünde \%21,53 azalma gözlenmiştir. Doğal agrega ile birlikte \%50 atık agrega kullanımı ile bu azalma, \%13,20 olmuştur. Geri dönüşüm agregası geleneksel betondan elde edildiğinde, atık agrega ile üretilen betonlarda normal betonlara kıyasla dinamik elastisite modülü değeri \%80'e varan oranlarda düşük olabilmektedir [33]. $\mathrm{Bu}$ durum göz önüne alındığında, silindirle sıkıştırılmış betonların geri dönüştürülmesinin, geri dönüştürülmüş geleneksel betona göre mekanik özelliklerde daha az bir değişim meydana getirdiği görülmektedir. Geri dönüştürülmüş SSB agregasının kalitesi, geri dönüştürülmüş normal beton agregasından daha iyi olduğundan, silindirle sıkıştırılmış betonlardan elde edilen agreganın beton özellikleri üzerindeki etkisi daha olumludur. Ayrıca, atık betonun ögütülmesi sonucunda elde edilen agreganın üzerinde bulunabilen harç kalıntıları, agreganın yassılık indeksi, yüzey pürüzlülüğü gibi yüzey özellikleri, şekli ve dokusu da üretilen beton performansı üzerinde etkili olmaktadır [34].

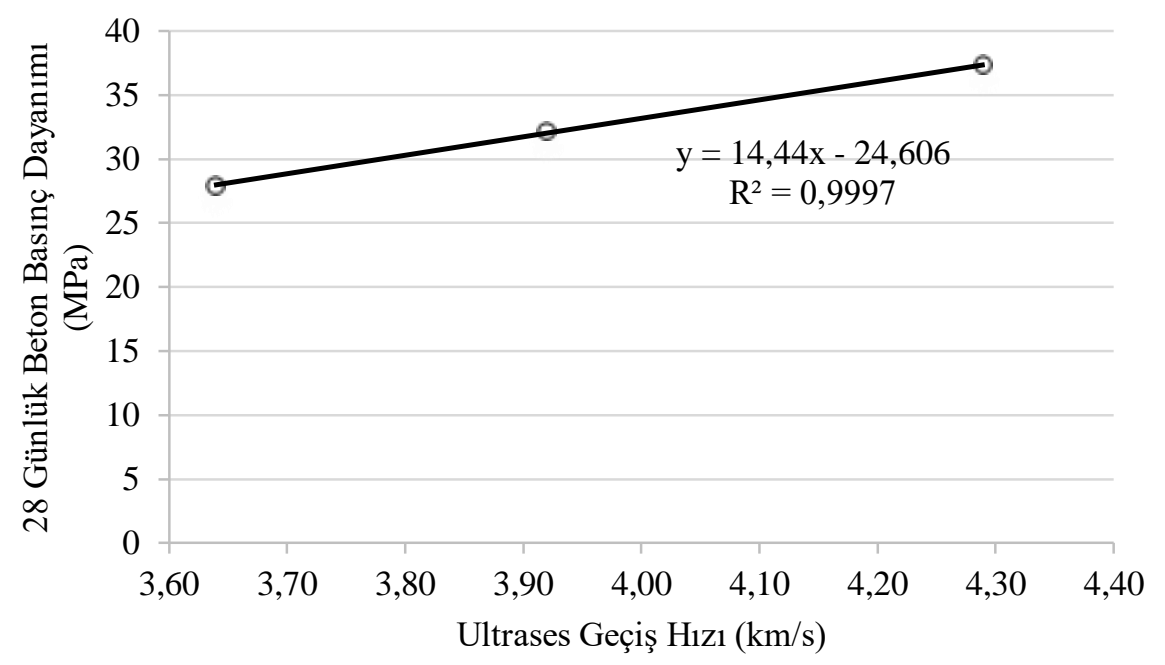

Şekil 2. Silindirle sıkıştırılmış betonlarda ultrases geçiş hızı ile beton basınç dayanımı arasındaki ilişki

Şekil 3'te silindirle sıkıştırılmış betonlarda, beton basınç dayanımı ile dinamik elastisite modülünün değişimi görülmektedir. Basınç dayanımı arttıkça, dinamik elastisite modülü değerinin de arttığı görülmüştür. 28 günlük beton basınç dayanımı ile betonun dinamik elastisite modülü arasındaki ilişkinin kuvvetli olduğu söylenebilir. Betonun mekanik özellikleri yalnızca karışım oranlarından değil, kullanılan iri agreganın özelliklerinden de doğrudan etkilenmektedir, bu nedenle uygulamaya bağlı olarak hedeflenen bir beton basınç dayanımı mevcutsa, geri dönüştürülmüş agrega kullanımında bu hususa ayrıca dikkat edilmelidir [35].

Şekil 4'te ultrases geçiş hızı ile aşınma miktarı arasındaki ilişki verilmiştir. Grafikte, ultrases geçiş hızı arttıkça yani beton boşluk oranı azaldıkça, aşınma miktarının da azaldığı görülmektedir.

Şekil 5'te birim hacim ağırlık ile aşınma miktarının değişimi gösterilmektedir. Üretilen SSB numunelerin birim hacim ağırlığı arttıkça aşınma miktarı azalmaktadır ancak bu ikisi arasındaki doğrusal ilişkinin zayıf olduğu söylenebilir. Özellikle yol inşaatı uygulamalarında, kullanılan malzemenin yüzey aşınmasının az olması gerekmektedir, ayrıca bu durum sürüş kolaylığı açısından da önemlidir. Aşınma kaybının az olmasıyla bakım-onarım maliyetleri azalacağı gibi bu onarımlar sırasında yolun trafiğe kapatılmasının yaratacağı ekonomik kayıplar da azaltılabilecektir. 


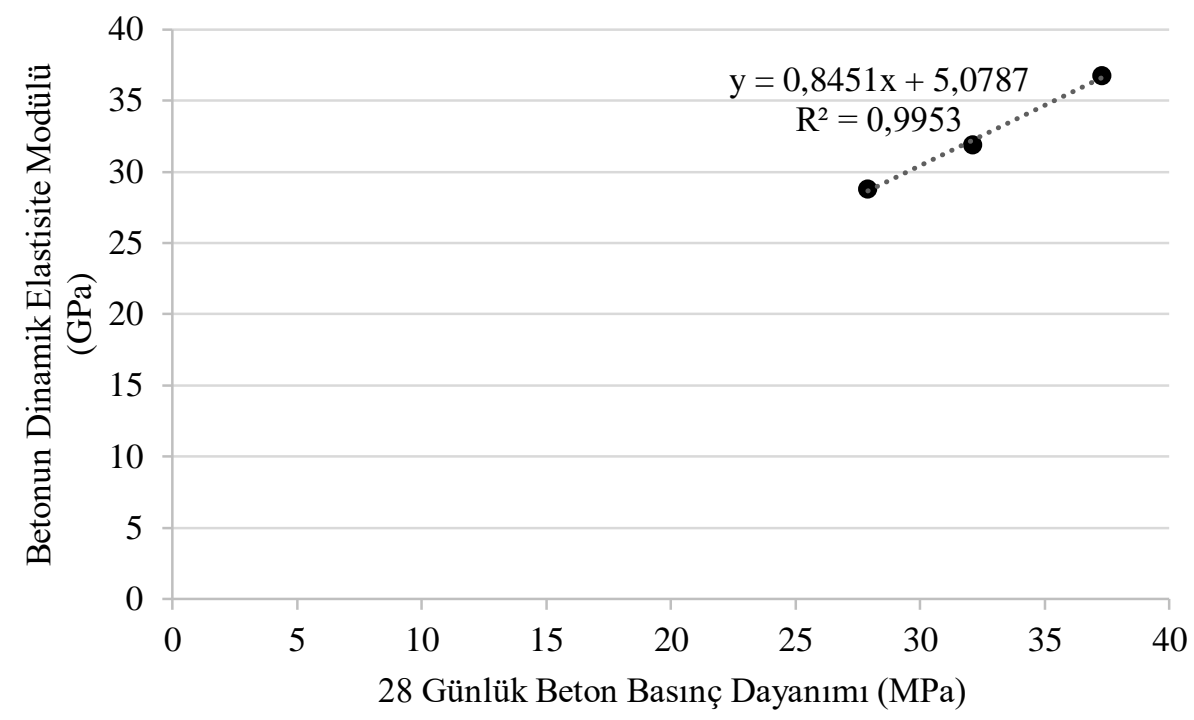

Şekil 3. Silindirle sıkıştırılmış betonlarda dinamik elastisite modülü ile basınç dayanımı arasındaki ilişki

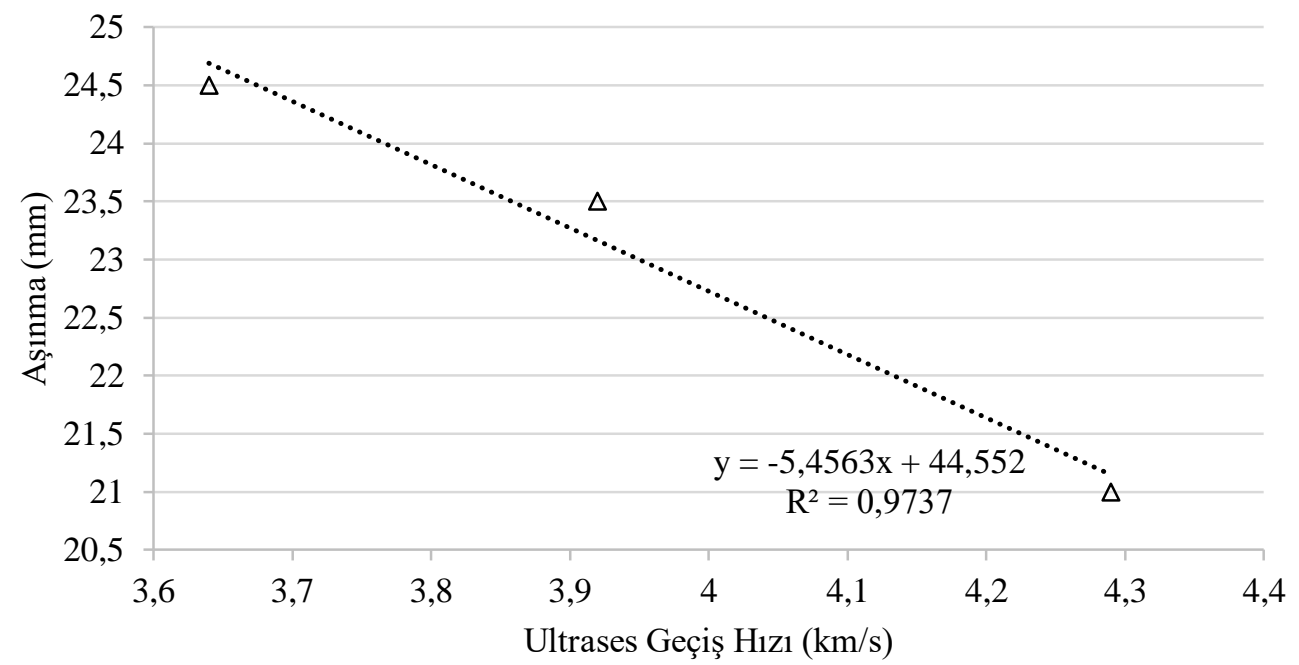

Şekil 4. Ultrases geçiş hızı ile aşınma miktarı arasındaki ilişki

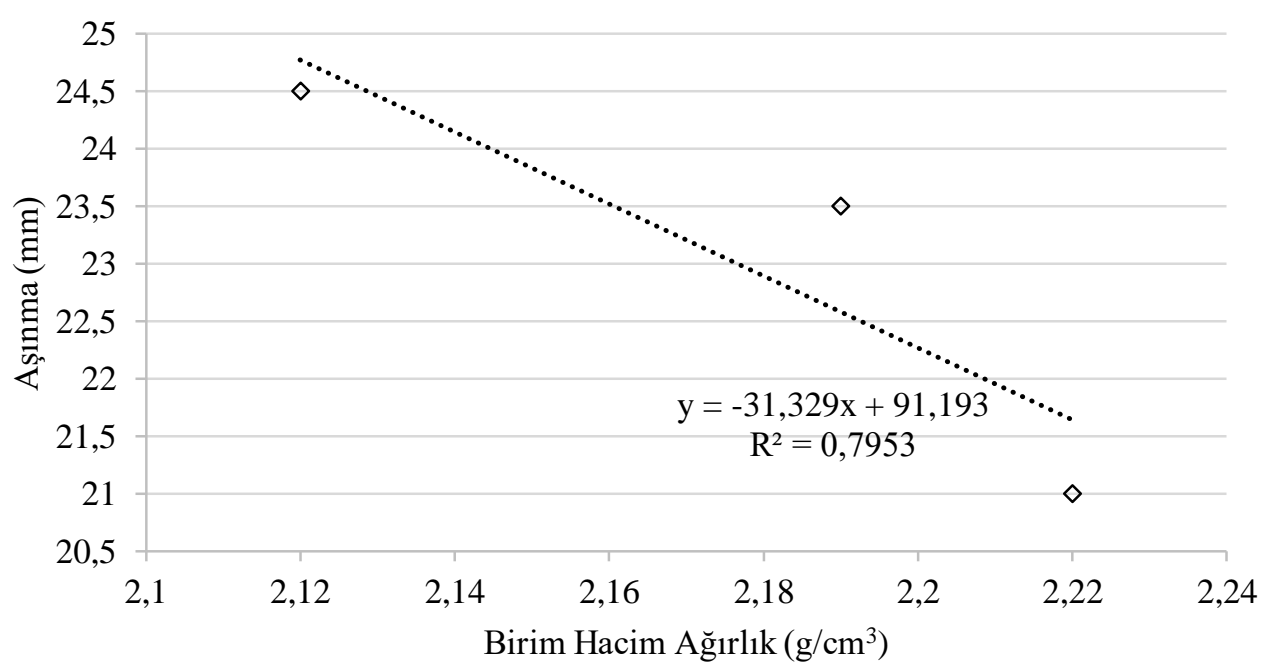

Şekil 5. Birim hacim ağırlık ile aşınma miktarı arasındaki ilişki 
Geri dönüştürülmüş agreganın birim hacim ağırlığının doğal agregadan düşük olması sebebiyle, geri dönüştürülmüş agrega ile üretilmiş örneklerin birim hacim ağırlık değerlerinin daha düşük olması beklenen bir sonuçtur. Karışımdaki atık agrega hacmi arttıkça betonun birim hacim ağırlığı azalacaktır. Bununla birlikte, atık agregaların aşınma kaybının fazla olması ve agrega-çimento aderansının daha düşük kaliteli agregalarda daha zayıf olması gibi etkenler, atık agrega ile üretilen betonların yüzey aşınmasının daha fazla olmasına sebep olmuştur. Atık betonda bulunan hidrate olmuş çimento taneleri agrega-çimento hamuru ara yüzeyini zayıflatmış olabilir. Öte yandan, bunun tam tersi sonuçların elde edildiği çalışmalar da mevcuttur [34]. Aşınma mukavemeti ile ilgili olarak doğal agrega ile üretilen referans betona göre geri dönüştürülmüş beton agregaları ile üretilen karışımların daha yüksek aşınma direncine sahip olduğu belirtilmiş, atık agregalı karışımlarda aşınma etkisine bağlı olarak daha az kesit kaybı ve kütle kaybı gerçekleştiği görülmüştür [36]. Bu sonucun elde edilmesinde iri geri dönüştürülmüş agreganın hem daha yüksek su emme kapasitesine hem de daha yüksek pürüzlülüğe sahip olmasının etkili olduğu, bu durumun harç-agrega ara yüzünü daha kohezif hale getirdiği ve bu nedenle atık agregalı beton için daha iyi aşınma direnci sağlayabildiği ifade edilmiştir [34].

\section{Sonuçlar}

Geri dönüştürülmüş silindirle sıkıştırılmış beton agregaları, kaynağının nispeten homojen olmasından ötürü, Los Angeles aşınma direnci, su emme değeri gibi beton kalitesini doğrudan etkileyen fiziksel özelliklerde nispeten homojenlik sağladığından bu atık agreganın beton üretiminde yeniden değerlendirilmesi mümkün olabilir. Yine de atık agregaların doğal agregalara göre su emme değerlerinin ve Los Angeles aşınma değerlerinin daha fazla olduğu, atık agregalarla üretilen betonlarda dayanım, dayanıklılık, işlenebilirlik ve beton kalitesi konularında doğal agrega ile üretilen betonlara kıyasla daha fazla sorunla karşılaşılabileceği göz önünde bulundurulmalıdır. Silindirle sıkıştırılmış beton üretiminde kullanılan atık agrega miktarı arttıkça, beton basınç dayanımında düşüş, dinamik elastisite modülünde azalma ve yüzey aşınma değerinde artma gerçekleşmiştir. Bunun yanı sıra, atık agrega kullanımı, ultrases geçiş hızında azalma, beton boşluk hacminde ve su emme değerlerinde artış ile sonuçlanmıştır. Atık agrega kullanımıyla betonun birim hacim ağırlığı azalmaktadır. Genel olarak atık agrega kullanımı, beton özelliklerini olumsuz etkilemekle birlikte, çevresel anlamda düşünüldüğünde, doğal kaynakların korunması anlamında yarar sağlamaktadır. Bu atıkların taşınması, depolanması ve çevreye zarar vermeyecek biçimde bertaraf edilmesi gerektiğinden atık agregaların beton içinde yeniden değerlendirilmesi, söz konusu süreçte de fayda getirmektedir. Ağır vasıta yoğunluğunun düşük olduğu yerlerde, tamamen atık agrega ile üretilen beton özellikleri yeterli olabilir. Dayanım ve dayanıklılık özelliklerinin iyileştirilmesi açısından, atık agregaların doğal agregalar ile belirli oranlarda karıştırılarak kullanılması bir çözüm olarak uygulanabilir. Uygun beton tasarımıyla, atık agregaların silindirle sıkıştırılmış beton üretiminde yeniden değerlendirilmesi, ekonomik ve sürdürülebilir bir beton üretimi sürecine katkı sağlayacaktır. Silindirle sıkıştırılmış atık beton agregaları ile yapılmış olan çalışmalar sınırlı olduğundan, bu konu üzerinde yapılacak araştırmaların arttırılması faydalı olacaktır.

\section{Yazarların Katkısı}

İsmail KILIÇ: Analizi planlamış, tasarlamış ve veri toplamıştır. Saadet Gökçe GÖK: Veri toplamış, verilerin analizini yaparak makaleyi yazmıştır.

\section{Çıkar Çatışması Beyanı}

Yazarlar arasında herhangi bir çıkar çatışması bulunmamaktadır.

\section{Araştırma ve Yayın Etiği Beyanı}

Yapılan çalışmada araştırma ve yayın etiğine uyulmuştur.

\section{Kaynaklar}

[1] Jingfu K., Chuncui H., Zhenli Z. 2009. Strength and Shrinkage Behaviors of Roller-Compacted 
Concrete with Rubber Additives. Materials and Structures/Materiaux et Constructions, 42 (8): $1117-1124$.

[2] Şengün E., Alam B., Sevin H. L., Aytaç A. H., Yaman İ. Ö. 2017. SSB Yolların Saha ve Laboratuvar Mekanik Performansının Karşılaştırılması. Hazır Beton Kongresi, Mayıs 2017, İstanbul.

[3] Wang C., Chen W., Hao H., Zhang S., Song R., Wang X. 2018. Experimental Investigations of Dynamic Compressive Properties of Roller Compacted Concrete (RCC). Construction and Building Materials, 168: 671-682.

[4] Wang X., Zhang S., Wang C., Liu F., Song R., Wei P. 2018b. Initial Damage Effect on Dynamic Compressive Behaviors of Roller Compacted Concrete (RCC) Under Impact Loadings. Construction and Building Materials, 186: 388-399.

[5] Wang X., Zhang S., Wang C., Song R., Shang C., Fang X. 2018. Experimental Investigation of The Size Effect of Layered Roller Compacted Concrete (RCC) Under High-Strain-Rate Loading. Construction and Building Materials, 165: 45-57.

[6] Arığlu N., Hatipoğlu D. D., Arığlu-Salmona M. O., Arığlu E. 2002. Sürdürülebilirlik Kavramı Anlayışında Beton Endüstrisinin İrdelenmesi.

https://yapimerkezi.com.tr/PdfDosyalari/ebdb652b-b1d9-4d19-af20-c28ded302fbd-7a5c38111160-4f5f-8669-beb507c87990.pdf. (Erişim tarihi: 09.02.2021).

[7] Drochytka R., Dufek Z., Michalčíková M., Hodul J. 2020. Study of Possibilities of Using Special Types of Building and Demolition Waste in Civil Engineering. Periodica Polytechnica Civil Engineering, 64 (1): 304-314.

[8] Atiş C. D. 2005. Strength Properties of High-Volume Fly Ash Roller Compacted and Workable Concrete, and Influence of Curing Condition. Cement and Concrete Research, 35 (6): 1112-1121.

[9] Mardani-Aghabaglou A., Ramyar K. 2013. Mechanical Properties of High-Volume Fly Ash Roller Compacted Concrete Designed By Maximum Density Method. Construction and Building Materials, 38: 356-364.

[10] Mardani-Aghabaglou A., Andıç-Çakır Ö., Ramyar K. 2013. Freeze-Thaw Resistance and Transport Properties of High-Volume Fly Ash Roller Compacted Concrete Designed by Maximum Density Method. Cement and Concrete Composites, 37 (1): 259-266.

[11] Cao C., Sun W., Qin H. 2000. Analysis on Strength and Fly Ash Effect of Roller-Compacted Concrete with High Volume Fly Ash. Cement and Concrete Research, 30 (1): 71-75.

[12] Adamu M., Mohammed B. S., Liew M. S. 2018. Mechanical Properties and Performance of High Volume Fly Ash Roller Compacted Concrete Containing Crumb Rubber and Nano Silica. Construction and Building Materials, 171: 521-538.

[13] Chi M., Huang R. 2014. Effect of Circulating Fluidized Bed Combustion Ash on the Properties of Roller Compacted Concrete. Cement and Concrete Composites, 45: 148-156.

[14] Modarres A., Hosseini Z. 2014. Mechanical Properties of Roller Compacted Concrete Containing Rice Husk Ash with Original and Recycled Asphalt Pavement Material. Materials and Design, 64: 227-236.

[15] Meddah A., Beddar M., Bali A. 2014. Use of Shredded Rubber Tire Aggregates for Roller Compacted Concrete Pavement. Journal of Cleaner Production, 72: 187-192.

[16] Lopez-Uceda A., Agrela F., Cabrera M., Ayuso J., López M. 2018. Mechanical Performance of Roller Compacted Concrete with Recycled Concrete Aggregates. Road Materials and Pavement Design, 19 (1): 36-55.

[17] Courard L., Michel F., Delhez P. 2010. Use of Concrete Road Recycled Aggregates for Roller Compacted Concrete. Construction and Building Materials, 24 (3): 390-395.

[18] Belleflamme M. 2004. Recycled Aggregates and CE Marking, Yüksek lisans tezi, Faculté des Sciences Appliquées, Université de Liège, 145.

[19] Levy S. M., Helene P. 2004. Durability of Recycled Aggregates Concrete: A Safe Way to Sustainable Development. Cem Concr Res, 34 (11): 1975-1980.

[20] Gómez-Soberón J. 2002. Porosity of Recycled Concrete with Substitution of Recycled Concrete Aggregate: An Experimental Study. Cem Concr Res, 32: 1301-1311.

[21] Debieb F., Courard L., Kenai S., Degeimbre R. 2009. Roller Compacted Concrete with Contaminated Recycled Aggregates. Construction and Building Materials, 23 (11): 3382-3387. 
[22] TS EN 1097-3. 1999. Agregaların Fiziksel ve Mekanik Özellikleri için Deneyler - Bölüm 3: Gevşek Yığın Yoğunluğunun ve Boşluk Hacminin Tayini. Türk Standartları Enstitüsü, Ankara.

[23] TS EN 1097-6. 2013. Agregaların Mekanik ve Fiziksel Özellikleri için Deneyler - Bölüm 6: Tane Yoğunluğu ve Su Emme Oranının Tayini. Türk Standartları Enstitüsü, Ankara.

[24] TS EN 1097-2. 2010. Agregaların Mekanik ve Fiziksel Özellikleri için Deneyler - Bölüm 2: Parçalanma Direncinin Tayini için Metotlar. Türk Standartları Enstitüsü, Ankara.

[25] TS 802. 2016. Beton Karışım Tasarımı Hesap Esasları. Türk Standartları Enstitüsü, Ankara.

[26] TS EN 12350-2. 2010. Beton - Taze Beton Deneyleri - Bölüm 2: Çökme (Slump) Deneyi. Türk Standartları Enstitüsü, Ankara.

[27] TS EN 12390-3. 2010. Beton - Sertleşmiş Beton Deneyleri - Bölüm 3: Deney Numunelerinin Basınç Dayanımının Tayini. Türk Standartları Enstitüsü, Ankara.

[28] ASTM C 597-16. 2016. Standard Test Method for Pulse Velocity Through Concrete. ASTM International, West Conshohocken, PA.

[29] TS EN 1342. 2013. Dış Zeminlere Döşenen Doğal Parke Taşları-Gerekler ve Deney Yöntemleri. TSE.

[30] ASTM C 1435/C 1435M-20. 2020. Standard Practice for Molding Roller-Compacted Concrete In Cylinder Molds Using A Vibrating Hammer. ASTM International, West Conshohocken, PA.

[31] Özturan T. 1988. Eski Beton Kırığı Agregalı Betonlar. Yapı Malzemesi Seminerleri, İTÜ İnşaat Fakültesi, İstanbul.

[32] Durmuş G., Şimşek O., Dayı M. 2009. Geri Dönüşümlü İri Agregaların Beton Özelliklerine Etkisi. Gazi Üniv. Müh. Mim. Fak. Der., 24 (1): 183-189.

[33] Topçu İ. B., Günçan N. F. 1995. Using Waste Concrete as Aggregate. Cement and Concrete Research, 25 (7): 1385-1390.

[34] Matias D., De Brito J., Rosa A., Pedro D. 2013. Mechanical Properties of Concrete Produced with Recycled Coarse Aggregates - Influence of the Use of Superplasticizers. Construction and Building Materials, 44: 101-109.

[35] Butler L., West J. S., Tighe S. L. 2013. Effect of Recycled Concrete Coarse Aggregate from Multiple Sources on the Hardened Properties of Concrete with Equivalent Compressive Strength. Construction and Building Materials, 47: 1292-1301.

[36] Evangelista L., De Brito J. 2007. Mechanical Behaviour of Concrete Made with Fine Recycled Concrete Aggregates. Cem Concr Compos, 29 (5): 397-401. 